\title{
DECRETO No 41.620/02, - AGREGAR - RS CARNES: UM ESTUDO DE CASO EM UMA EMPRESA DE ABATE DE BOVINOS, OVINOS E BUFALINOS
}

\author{
Law No 41.620 / 02, - Agregar-RS Meat: A Case Study in a Cow, \\ Sheep and Buffalo Slaughtering Company
}

\begin{abstract}
RESUMO
Com o objetivo de incentivar as empresas abatedora de bovinos, ovinos e bufalinos o Estado do Rio Grande do Sul, através do Decreto $n^{\circ} 41.620 / 02$ determinou o benefício do crédito presumido de ICMS com base no Decreto $n^{\circ} 37.699 / 98$ do RICMS/RS para as empresas que atendem este ramo de atividade, localizadas neste Estado. Os objetivos propostos nesta pesquisa foram de analisar e exemplificar a importância de a empresa manter as informações pertinentes ao AGREGAR-RS CARNES de acordo com a legislação vigente para obter o benefício previsto no Decreto $n^{\circ} 41.620 / 02$. A metodologia utilizada nesta pesquisa caracteriza-se como aplicada quanto a sua natureza, descritiva e exploratória em relação aos objetivos. Para os procedimentos técnicos utilizouse de pesquisa bibliográfica e documental, com entrevistas não padronizadas e estudo de caso, através de abordagem quantitativa e qualitativa. Os resultados obtidos através das análises dos dados disponibilizados para o período de janeiro de 2015 até julho de 2016 demonstraram que houve uma não apropriação do crédito presumido de ICMS devido às informações não estarem corretas no Programa AGREGAR-RS CARNES.
\end{abstract}

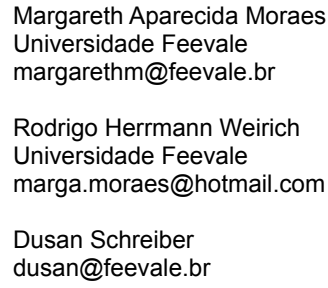

\section{ABSTRACT}

The State of Rio Grande do Sul, through Decree No. 41.620 / 02, determined the benefit of the presumed ICMS credit based on Decree No. 37.699 / 98 of the RICMS / RS to encourage cattle, sheep and buffalo the companies that attend this branch of activity, located in this State. The objectives proposed in this research were to analyze and exemplify the importance of the company to keep pertinent information to AGREGAR-RS CARNES in accordance with the current legislation to obtain the benefit provided in Decree No. 41.620 / 02. The methodology used in this research is characterized as applied in nature, descriptive and exploratory in relation to the objectives. For the technical procedures we used bibliographical and documentary research, with non-standard interviews and case study, through a quantitative and qualitative approach. The results obtained through the analysis of data made available for the period from January 2015 to July 2016 demonstrated that there was a non-appropriation of the presumed ICMS credit due to the information not being correct in the AGREGAR-RS CARNES Program.

Palavras-chave: Crédito Presumido. Tributo Estadual. Diferimento.

Keywords: Presumed Credit. State Tax. Deferral.

\section{INTRODUÇÃO}

A alta carga tributária e a quantidade de tributos e regras regidas por normas fazem com que o Sistema Tributário Nacional se torne um tanto quanto complexo. Isso ocorre com o elevado ônus fiscal e consequentemente contábil, atrelado as constantes alterações na legislação, que acabam acarretando em impactos na economia e nos resultados das organizações. O planejamento tributário é considerado um meio legal para reduzir os despendios com o recolhimento de tributos, o que evita a prática da evasão fiscal (sonegação fiscal). Para um bom planejamento tributário, a empresa deve estar atenta à legislação vigente, o que requer conhecimento e acompanhamento por parte dos usuários responsáveis. 
Dentro do planejamento tributário, a empresa também pode buscar benefícios fiscais que reduzam a carga tributária. Um desses benefícios, concedido pelo Estado do Rio Grande do Sul, são os créditos presumidos de Imposto sobre Operações relativas à Circulação de Mercadorias e sobre Prestação de Serviço de Transporte Intermunicipal e de Comunicação (ICMS). Os créditos presumidos de ICMS no Estado do Rio Grande do Sul são benefícios para as empresas que se enquadram dentro do art. 32 do Decreto $n^{\circ}$ 37.699/97 (RIO GRANDE DO SUL, 1997) do Regulamento do Imposto sobre Operações relativas à Circulação de Mercadorias do Estado do Rio Grande do Sul (RICMS/RS) e do Decreto ${ }^{\circ} 41.620 / 02$ (RIO GRANDE DO SUL, 2002).

Dentre os ramos de atividades que podem se beneficiar com os créditos presumidos de ICMS, encontra-se o abate de bovinos, ovinos e bufalinos. A escolha desse enfoque ocorreu tendo em vista a relevância do setor agrupecuário para a economia rio grandense (FARSUL, 2017; ROCHA; PARRÉ, 2009). Assim, tendo em vista os tópicos abordados até então, a presente-pesquisa busca responder a seguinte questão: Qual é o impacto sobre a carga tributária decorrente da desatualização das informações junto ao controle do Programa Estadual de Desenvolvimento, Coordenação e Qualidade do Sistema Agroindustrial da Carne de Gado Vacum, Ovino e Bufalino (AGREGARRS CARNES)?

Para responder a esse problema, buscou-se, então contextualizar o art. 32 do RICMS/RS e o Decreto $n^{\circ}$ 41.620/02, como fonte para levantamento de informações e para a compreensão desta pesquisa; analisar e comparar as informações obtidas de uma empresa de grande porte do ramo de abatedores de bovino, ovinos e bufalinos, identificada neste trabalho como Empresa Z, no período de janeiro de 2015 até julho de 2016, visando verificar se a empresa está de acordo com a legislação vigente para a obtenção do benefício fiscal compreendido pelo art. 32 do RICMS/RS; identificar a existência de possíveis erros no período analisado e evidenciar possível impacto sobre a carga tributária decorrente de desatualização das informações junto ao controle sobre o benefício fiscal do AGREGAR-RS CARNES.

A metodologia estabelecida para o desenvolvimento desta pesquisa caracteriza-se como aplicada, quanto à sua natureza, e como descritiva, quanto aos seus objetivos. Quanto aos procedimentos técnicos, realizou-se um estudo de caso em que a coleta de dados foi realizada mediante a observações diretas e indiretas, coleta documental e entrevistas não estruturadas, através de uma abordagem qualitativa.
Assim, de forma a alcançar os objetivos propostos, a pesquisa está estruturada de forma a trazer, posteriormente a esta primeira seção de introdução, um pequeno referencial sobre o AGREGAR-RS CARNES, suas particularidades e formas de adesão ao Programa AGREGARRS CARNE. Na seção 3 descreve-se o método utilizado nesta pesquisa, seguida da Análise dos dados na seção 4 e as considerações finais, na seção 5 .

\section{AGREGAR CARNES}

O Programa AGREGAR-RS CARNES foi criado pelo Decreto ${ }^{\circ} 41.620$, de 20 de maio de 2002 (RIO GRANDE DO SUL, 2002). Sua criação teve por objetivo aumentar o abate realizado sob inspeção sanitária oficial e o desenvolvimento e a competitividade da cadeia produtiva de carnes no Rio Grande do Sul. Assim, este Decreto visa incentivar o agronegócio do Estado, com o aumento do consumo de carne, conforme o seu art. $1^{\circ}$, Incisos I ao IV (RIO GRANDE DO SUL, 2002). Além disso, visa incentivar as empresas a terem as certificações sanitárias, maior qualidade dos produtos oferecidos e projetos de qualificação da sua mão-de-obra, conforme os Incisos $\mathrm{V}$ ao VIII do art. $1^{\circ}$ (RIO GRANDE DO SUL, 2002).

Dessa forma, destaca-se que o Programa AGREGAR-RS CARNES, também em seu art. $1^{\circ}$, nos Incisos $\mathrm{XI}$ ao $\mathrm{XV}$, prevê o aumento da produtividade Gaúcha, com a elevação da qualidade dos produtos, proporcionando incentivo às micro e pequenas empresa do Estado. Além disso, destaca a promoção de maior controle sobre a sonegação de tributos e o abigeato de bovino, ovino e bufalinos. (RIO GRANDE DO SUL, 2002).

No que tange ao ônus tributário o Programa AGREGAR-RS CARNES possui dois tipos de crédito para as empresas, sendo estes o crédito presumido sobre as aquisições do gado vivo e o crédito presumido sobre as vendas de produtos comestíveis resultantes do abate. Os créditos do AGREGAR-RS CARNES estão previstos no RICMS/RS, no art. 32, Inciso XI onde está determinado a apropriação do crédito do AGREGAR-RS CARNES, e os percentuais que a empresa poderá aplicar sobre a compra ou a venda da carne que resultará no benefício do crédito fiscal estabelecido por este programa(RIO GRANDE DO SUL, 1997).

\subsection{Créditos Fiscais Agregar-RS Carnes}

Em relação ao crédito presumido do ICMS do Programa AGREGAR-RS CARNES, destaca-se que este não se dará no momento da aquisição do gado. A empresa abatedora só poderá fazer a glosa do crédito de ICMS 
após o abate do bovino, ovino ou bufalino. Sobre o total da Nota Fiscal do Produtor Rural, a empresa adquirente poderá se creditar de 3,6\%, sobre as aquisições de gado oriundas do Rio Grande do Sul. Caso o bovino venha de outra Unidade da Federação, não poderá fazer o crédito do ICMS (RIO GRANDE DO SUL, 1997).

Ressalta-se que, conforme Nota 4 A do Livro 1, art. $32^{\circ}$ do RICMS/RS, da receita auferida decorrente das exportações deverá ser estornado o crédito proporcional à quantidade de quilogramas $(\mathrm{kg})$ exportados, salvo caso o produto exportado não seja comestível, como é o caso do couro, entre outros produtos (RIO GRANDE DO SUL, 1997). A Nota 5, deste mesmo artigo, destaca que o crédito está previsto também caso a empresa já compre bovinos, ovinos e bufalinos abatidos de outros abatedores habilitados no programa (RIO GRANDE DO SUL, 1997).

A seguir, na Figura 1, exemplifica-se como se geram as apurações para o crédito do AGREGAR-RS CARNES sobre as entradas dos animais. O sistema da empresa gera todos as notas neste relatório, de acordo com os lançamentos feitos pelos responsáveis. O crédito só será considerado após o abate do bovino, ovino ou bufalino pelo peso carcaça, representado na Figura 1 como PESO CARC. Salienta-se que o peso evidenciado na Figura 1 refere-se ao peso liquido do bovino, já descontadas as partes não comestíveis.

Após apurado o crédito referente à entrada do animal, passa-se a analisar o crédito que a empresa abatedora terá direito de fazer sobre as vendas dos produtos comestíveis resultante do abate. $\mathrm{Na}$ apuração deste crédito, a empresa receberá dois percentuais, que são determinados de acordo com os critérios relacionados na forma que a mercadoria está sendo vendida: embalada (quando a carne é separada por tipos de corte), ou peça inteira (quando vendida sem cortes estabelecidos), considerando-se a peça como dianteiro ou traseiro do animal abatido. Para as carnes embaladas, o crédito sobre as vendas é de $4 \%$ e sobre as vendas de peças inteiras, é de 3\%, conforme determinado no Livro I, Art. $32^{\circ}$, Inciso XI, Alínea C do RICMS/RS (RIO GRANDE DO SUL, 1997).

O crédito fiscal será reduzido a $3 \%$ quando os referidos produtos não estiverem embalados em cortes, conforme a Nota 3 deste artigo (RIO GRANDE DO SUL, 1997). Nas aquisições de carne de outros abatedores, caso a mercadoria não sofra nenhum tipo de industrialização, a empresa não poderá se beneficiar de nenhum dos dois percentuais previstos, conforme no Livro I, Art. $32^{\circ}$, Inciso XI, Alínea C, Nota 04 do RICMS/RS (RIO GRANDE DO SUL, 1997).

A seguir, a Figura 2 apresenta um exemplo de como se gera o crédito referente às vendas dos produtos resultantes do abate. Neste exemplo é possível observar, como descrito no Decreto ${ }^{\circ}$ 41.620/02 (RIO GRANDE DO SUL, 2002), que a empresa poderá se beneficiar de dois percentuais: o de $3 \%$ quando a peça do bovino for inteira, ou o de $4 \%$ quando as peças foram embaladas.

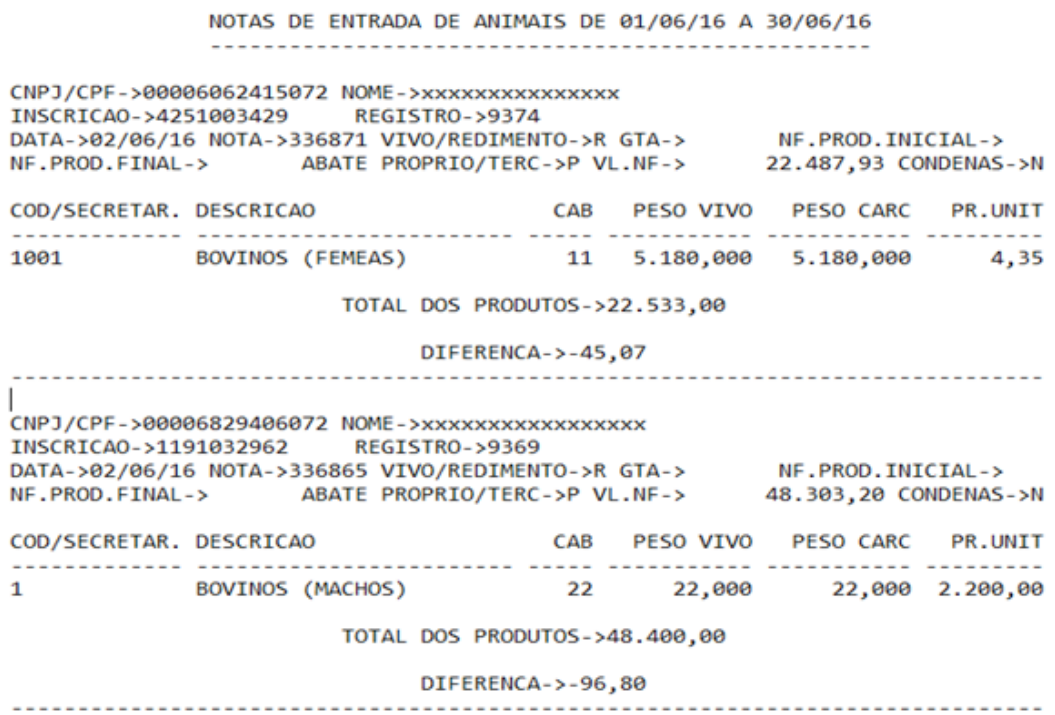

FIGURA 1 - Controle de notas de entrada de animais

Fonte: Sistema AGREGAR-RS CARNES

Organizações Rurais \& Agroindustriais, Lavras, v. 21, n. 1-3, p. 52-64, 2019 
Para que o sistema de gestão da empresa trabalhe em conjunto com o programa do Ministério da Agricultura, o responsável pelo registro dos produtos produzidos deve vincular o seu código de venda com os códigos definidos pelo programa do AGREGAR-RS CARNES (os códigos de produtos que estão nas Figuras 1 e 2 são os do Programa AGREGAR-RS CARNES).

Na programação dos vínculos, o responsável deve ter o cuidado de verificar se a peça é considerada embalada ou não, pois uma informação errada como essa pode gerar um crédito a mais para a empresa e este procedimento pode ser considerado como sonegação fiscal. Na hipótese de a empresa abatedora receber devoluções de venda, deverá fazer o estorno do crédito do Agregar Saídas, pois se não o fizer, a empresa estará se beneficiando indevidamente do crédito presumido do ICMS.

No final de cada mês a empresa deverá gerar um relatório simplificado dos registros de entradas e saídas, o qual será transmitido para o Ministério da Agricultura. A Figura 3 apresenta um exemplo do cálculo que é feito para se apurar o valor que a empresa poderá se creditar sobre o AGREGAR-RS CARNES, entradas e saídas.

Para a empresa se beneficiar dos créditos presumidos de ICMS, terá que seguir algumas normas que a Coordenadoria de Inspeção de Produtos de Origem Animal (CISPOA) estabelece. A CISPOA é um órgão da Secretaria da Agricultura, Pecuária e Agronegócio do Estado do Rio Grande do Sul. A CISPOA é responsável pelas inspeções dos produtos de origem animal que são comercializados dentro do estado do Rio Grande do Sul (SECRETARIADA
AGRICULTURA, PECUÁRIA E IRRIGAÇÃO, 2016). Conforme está descrito no art. $4^{\circ} \mathrm{e}$ seus incisos do Decreto $\mathrm{n}^{\mathrm{o}} 41.620$, de 20 de maio de 2002.

Art. $4^{\circ} \mathrm{O}$ Conselho de Administração expedirá, aos abatedores que cumprirem os requisitos, Carta de Habilitação Geral para participação no Programa, conforme segue:

I - aos micro e pequenos abatedores com faturamento anual igual ao limite estabelecido em Lei Estadual para Empresas de Pequeno Porte - EPP -, excluindo-se o faturamento proveniente de abate sanitário determinado pela autoridade sanitária e que:

a)apresentarem cadastro na forma estabelecida pelo Conselho de Administração;

b)apresentarem proposta de adesão ao Programa declarando total concordância com as ações de monitoramento estabelecidas pelo Conselho de Administração;

c)apresentarem certificado de conformidade com a Norma Técnica da Coordenaria de Inspeção de Produtos de Origem Animal - CISPOA -, para Instalações e Equipamentos de Micro Matadouros-Frigoríficos de Bovinos, Suínos e Ovinos, expedido pelo Departamento de Produção Animal da Secretaria da Agricultura e Abastecimento, ou firmado por empresa ou profissional habilitado naquele Departamento;

d)apresentarem comprovação de regularidade das obrigações estipuladas em convenções e acordos coletivos de trabalho firmados com sindicatos de trabalhadores afins, assim como de sentenças normativas, homologatórias de acordos ou não, mediante declaração da própria requerente, nos termos definidos pelo Conselho de Administração; e) tiverem aprovada a proposta de adesão pelo Conselho de Administração; (RIO GRANDE DO SUL, 2002)

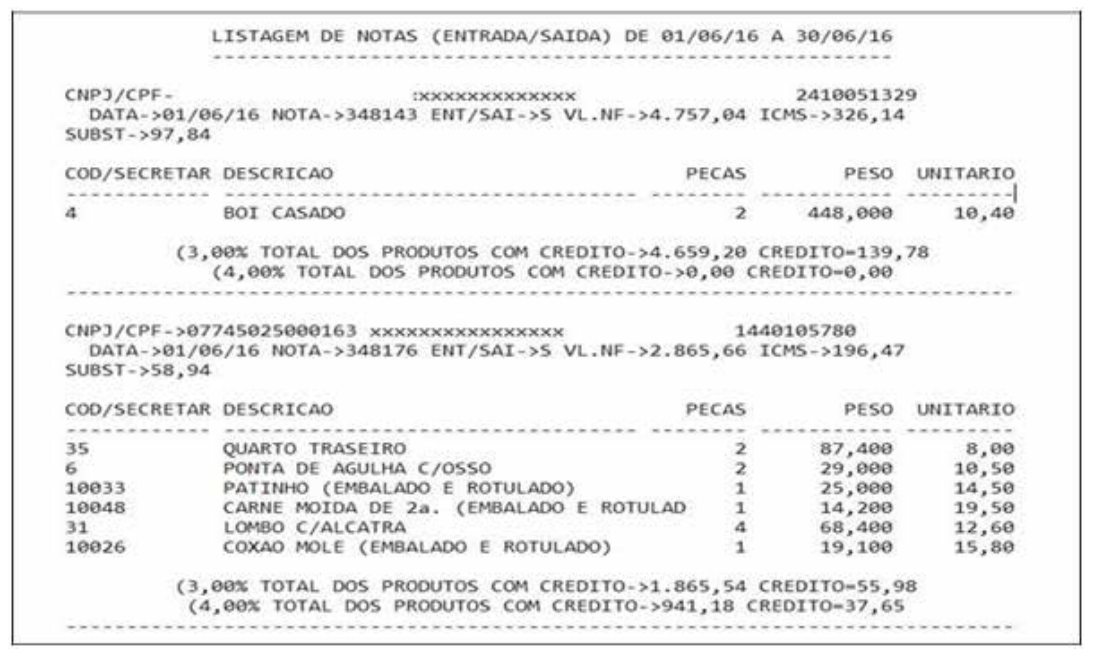

FIGURA 2 - Listagem de notas de saída

Fonte: Sistema AGREGAR-RS CARNES

Organizações Rurais \& Agroindustriais, Lavras, v. 21, n. 1-3, p. 52-64, 2019 


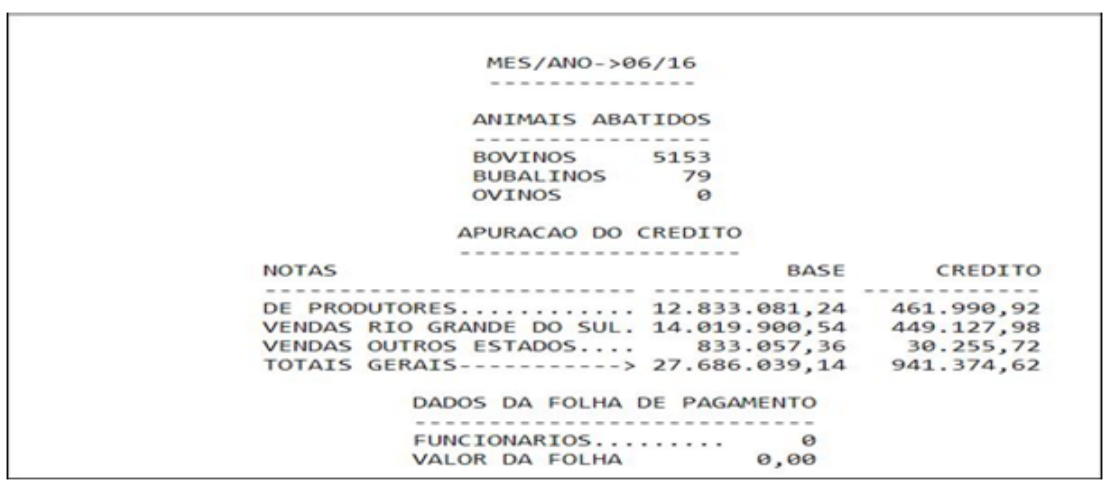

FIGURA 3 - Relatório Agregar Animais Abatidos Fonte: Sistema AGREGAR-RS CARNES

Os demais abatedores que não se enquadrarem no art. 4 Inciso I, deverão proceder da seguinte maneira, conforme o Inciso II do mesmo artigo:

\section{II - aos demais abatedores que:}

a) apresentarem cadastro na forma estabelecida pelo Conselho de Administração;

b)apresentarem proposta de adesão ao Programa declarando total concordância com as ações de monitoramento estabelecidas pelo Conselho de Administração;

c) apresentarem certificado de conformidade com a Norma Técnica da Coordenaria de Inspeção de Produtos de Origem Animal - CISPOA - para Instalações e Equipamentos de Matadouros-Frigoríficos de Bovinos e Bubalinos, expedido pelo Departamento de Produção Animal da Secretaria da Agricultura e Abastecimento, ou firmado por empresa ou profissional habilitado naquele Departamento;

d)apresentarem comprovação de regularidade das obrigações estipuladas em convenções e acordos coletivos de trabalho firmados com sindicatos de trabalhadores afins, assim como de sentenças normativas, homologatórias de acordos ou não, mediante declaração da própria requerente, nos termos definidos pelo Conselho de Administração; e) tiverem aprovada a proposta de adesão pelo Conselho de Administração. (RIO GRANDE DO SUL, 2002)

O registro no Serviço de Inspeção Federal (SIF), está vinculado ao Departamento de Inspeção de Produtos de Origem Animal (DIPOA), sendo ambos responsáveis por assegurar a qualidade dos produtos de origem animal. Atualmente, o SIF tem atuação em mais de 4 mil estabelecimentos brasileiros, sendo que 3.244 estabelecimentos que recebem o selo do SIF e 1.705 estabelecimentos relacionados a receber a certificação, todos estão sob a supervisão da DIPOA(MINISTÉRIO DAAGRICULTURA, 2016b; MINISTÉRIO DA AGRICULTURA, 2016e).
Ressalta-se que todo o produto de origem animal e que estiver sendo comercializado com o selo SIF tem a garantia de ser um produto inspecionado. Cada empresa recebe um número que deve ficar no centro do selo SIF. Assim, todos os produtos de origem animal são registrados e aprovados pelo SIF, visando garantir e assegurar produtos com certificação sanitária dentro das legislações nacionais e internacionais (BRASIL, 1952; MINISTÉRIO DA AGRICULTURA, 2016e).

A DIPOA é a instância central e competente pela inspeção de produtos de origem animal no país, sendo ela subordinada administrativamente à Secretaria de Defesa Agropecuária (SDA). A DIPOA é responsável pela elaboração das diretrizes de ação governamental para a inspeção e fiscalização, contribuindo para formação da política agrícola do Brasil (BRASIL, 1950; MINISTÉRIO DA AGRICULTURA, 2016b).

O Sistema de Informações Gerenciais do Serviço de Inspeção Federal (SIGSIF), foi criado em 2003, como uma ferramenta de gerenciamento do SIF e automação de processos de trabalho. Com este novo sistema, o Ministério da Agricultura consegue visualizar e fiscalizar os estabelecimentos relacionados em relação às informações de abate, produção, comercialização, recepção de matéria prima, rótulos analisados, certificados e guias de trânsito (MINISTÉRIO DA AGRICULTURA, 2016g).

O Ministério da Agricultura, através da Portaria $\mathrm{n}^{\circ} 185$ de 2008, criou a Comissão Técnica Permanente de Bem-Estar Animal (CTBEA), responsável pelas questões relativas ao bem-estar dos animais. Uma das atribuições do CTBEA é a divulgação e a proposição de boas práticas no manejo dos animais, alinhadas com a legislação Brasileira (MINISTÉRIO DA AGRICULTURA, 2016a). 
Outra importante ferramenta que a empresa tem é o programa de rastreabilidade dos animais adquiridos. Para a rastreabilidade dos bovinos, existe o programa Sistema Brasileiro de Identificação e Certificação de Bovinos e Bufalinos (SISBOV), utilizado para a identificação individual de bovinos e bufalinos em propriedades rurais que tenham o interesse em vender os animais para os abatedores (MINISTÉRIO DAAGRICULTURA, 2016f).

A CISPOA é responsável pela liberação da licença para os frigoríficos, foram criadas normas técnicas que devem ser seguidas quanto a novas instalações ou reformas que venham a ser feitas. Uma das normas que a empresa deve seguir antes do abate dos animais é que todos devem passar por uma inspeção sanitária para a averiguação da existência de machucados ou feridas. Após, eles recebem um banho com soluções químicas para a limpeza. E só após essas etapas serão encaminhados às salas de abate (MINISTÉRIO DA AGRICULTURA, 2016d).

$\mathrm{Na}$ sala de abate, todos os aninais passam por um novo processo de inspeção, conhecido como Departamento de Inspeção Final (DIF), para a verificação da possibilidade de as carnes estarem contaminadas. Com a confirmação de que o animal está contaminado com algum vírus, o mesmo deve ser encaminhado para o forno crematório para incineração (MINISTÉRIO DAAGRICULTURA, 2016d; MINISTÉRIO DA AGRICULTURA, 2016c).

\section{MÉTODO}

A seguir classifica-se o presente estudo em relação a sua natureza, seus objetivos, procedimentos técnicos e quanto à abordagem do problema.

Quanto a natureza, tendo em vista que Prodanov e Freitas (2009) destacam que uma pesquisa pode ser de natureza básica ou aplicada. A básica consiste em criar novos conhecimentos para auxiliar no avanço da ciência, sem a realização da prática prevista, envolvendo interesses universais. A aplicada, por sua vez, consiste em criar conhecimentos com a realização da parte prática voltada a solucionar problemas específicos, envolvendo apenas interesses locais. Portanto, este trabalho é uma pesquisa de natureza aplicada, pois visa a um conhecimento sobre a legislação referente ao AGREGARRS CARNES, programa instituído pelo Decreto $n^{\circ} 41.620$, de 20 de maio de 2002 (RIO GRANDE DO SUL, 2002).

No que tange os objetivos da pesquisa, este estudo caracteriza-se como descritivo, pois se buscou descrever como a empresa deve proceder para se creditar do ICMS do AGREGAR-RS CARNES, e de como devem ser os requisitos para se ter este crédito. Sendo assim, conforme
Prodanov e Freitas (2013, p. 63), esta pesquisa pode ser classificada como descritiva a medida que se "observa, registra, analisa e ordena dados, sem manipulá-los, isto é, sem a interferência do pesquisador".

Em relação aos procedimentos técnicos, optou-se por um estudo de caso que, conforme Raupp e Beuren (2006) é aquele em que se aprofunda a investigação sobre um determinado assunto específico. Neste estudo, conforme recomendado por Prodanov e Freitas (2009), são utilizadas diversas fontes para a coleta de dados, entre elas as observações diretas ou indiretas, coleta documental e entrevistas não estruturadas.

No que se refere a abordagem, a pesquisa pode ser classificada em qualitativa, pois interpreta e atribui significados aos eventos e estabelece contato diretamente com o objeto de estudo. Os dados desse tipo de pesquisa são descritivos, pois retratam a realidade estudada (PRODANOV; FREITAS, 2009). No caso deste trabalho, a partir de dados coletados, foram analisados os procedimentos adotados pela empresa.

Em relação a coleta de dados, nesta pesquisa, tendo em vista legislação do RICMS/RS e o Decreto $n^{\circ} 41.620 / 02$, referente ao Programa AGREGAR-RS CARNES (RIO GRANDE DO SUL, 2002) realizou-se a análise para verificar se a empresa foco do estudo está tomando todas as medidas necessárias para se manter no programa AGREGAR-RS CARNES e se a empresa está atendendo a legislação. A coleta de dados ocorreu por meio de triangulações de fontes, conforme sugerido por Yin (2010), a saber, entrevistas, levantamento documental e observação não participante. Realizou-se uma entrevista não estruturada com um dos responsáveis do Ministério da Agricultura, que disponibilizou algumas informações sobre como as empresas devem proceder para se enquadrar no Programa AGREGAR-RS CARNES.

A análise de conteúdo segundo (BARDIN, 2011), designa técnicas de análise das comunicações, visando obter por meios sistemáticos de comunicações indicadores que permitam a interferência de conhecimento das mensagens obtidas.

\section{ESTUDO DE CASO}

Neste estudo foi realizada análise dos registros internos da Empresa Z (anonimato exigido pela organização investigada), objetivando identificar, se a mesma, está de acordo com as regras e a legislação vigente quanto ao enquadramento no Programa AGREGAR-RS CARNES. A empresa é do ramo de abate de bovinos, ovinos e bufalinos. A empresa está situada na Região Metropolitana de Porto Alegre/RS, fundada 
em 1971, tributada pelo Lucro Real Trimestral com base na legislação vigente já analisados nesta pesquisa. Praticamente todos os produtos comercializados pela Empresa Z são tributados à alíquota zero de PIS e COFINS, conforme a Lei $\mathrm{n}^{\mathrm{o}} 12.839 / 13$ (BRASIL, 2013) já citada no capitulo do PIS e COFINS não cumulativo. Hoje a empresa conta com mais de 250 funcionários, divididos em diversos setores.

A tributação pelo Lucro Real Trimestral segue todas as regras conforme o artigo 247 do RIR/99, os ajustes para o lucro líquido estão de acordo com o art. 249 do RIR/99. Os créditos fiscais de PIS e COFINS conforme Rezende, Pereira e Alencar (2010), são feitos sobre os insumos utilizados no processo de fabricação, bem como a energia elétrica consumida e as depreciações ou amortizações do ativo imobilizado do parque fabril da Empresa Z.

A empresa conta com uma frota própria de caminhões para o transporte dos animais da fazenda do produtor até o frigorífico. Os motoristas são treinados e capacitados para conduzirem os veículos corretamente, tendo o cuidado de assegurar o bem-estar do animal, o que diminui o estresse e evitar lesões no transporte (MINISTÉRIO DA AGRICULTURA, 2016a).

Seu abate nos meses de junho e julho fica em aproximadamente 5.000 cabeças de bovinos e bufalinos e de 6.000 cabeças nos demais meses do ano. Todos os animais, antes e após o abate, passam pelo controle de inspeção animal, onde é analisado se a carne pode seguir para os demais processos do pós abate ou deve ser descartada, pois pode haver algum risco de contaminação deste animal ou, até mesmo, nos demais que já foram abatidos. Após o processo de abate, as carcaças são conduzidas às câmeras de resfriamento, onde ficam por aproximadamente 24 horas, garantindo uma temperatura ideal no interior da massa muscular dos bovinos (MINISTÉRIO DA AGRICULTURA, 2016d).

Após as 24 horas que as carcaças ficam nas câmaras de resfriamento, elas são destinadas aos próximos setores. Um dos setores é a desossa, onde as peças são separadas em cortes e outras são deixadas em meia carcaça. As meias carcaças são destinas às câmaras de resfriamento ou congelamento. As peças em cortes específicos, como picanha entre outros, passam pelo processo de embalagem e estocagem nas câmaras de resfriamento ou congelamento, para posterior comercialização (MINISTÉRIO DAAGRICULTURA, 2016d).

A matéria prima da Empresa $Z$ vem de diversas regiões do Estado do Rio Grande do Sul e o seu produto final é comercializado em aproximadamente $91 \%$ no Estado do Rio Grande do Sul, 8\% é destinado para as demais regiões do país e $1 \%$ é destinado a exportações (Figura 4). As exportações têm por destino países da Ásia, que só adquirem as miudezas dos bovinos, como aorta, fígado, tendões e medula.

\begin{tabular}{|c|c|c|c|c|c|c|c|c|c|c|}
\hline \multicolumn{11}{|c|}{ Vendas periodo de 2015 até julho de 2016.} \\
\hline Mês & Rio Grande do Sul & $\%$ & \multicolumn{2}{|c|}{ Demais Estados } & $\%$ & \multicolumn{2}{|c|}{ Exportação } & $\%$ & \multicolumn{2}{|r|}{ Total } \\
\hline $\mathrm{jan} / 15$ & RS $16.663 .948,18$ & $95 \%$ & RS & $913.238,00$ & $5 \%$ & RS & - & $0 \%$ & RS & $17.577 .186,18$ \\
\hline fev/15 & RS $14.267 .777,50$ & $98 \%$ & RS & $231.521,36$ & $2 \%$ & RS & - & $0 \%$ & RS & $14.499 .298,86$ \\
\hline $\mathrm{mar} / 15$ & RS $14.506 .787,02$ & $98 \%$ & RS & $356.496,59$ & $2 \%$ & $\mathbf{R S}$ & - & $0 \%$ & $\mathrm{R} S$ & $14.863 .283,61$ \\
\hline$a b r / 15$ & RS $13.169 .572,19$ & $96 \%$ & RS & $505.436,09$ & $4 \%$ & RS & - & $0 \%$ & RS & $13.675 .008,28$ \\
\hline $\mathrm{mai} / 15$ & RS $13.519 .325,73$ & $95 \%$ & RS & $778.294,61$ & $5 \%$ & RS & - & $0 \%$ & RS & $14.297 .620,34$ \\
\hline jun/15 & RS $14.321 .081,89$ & $97 \%$ & $\mathrm{RS}$ & $496.541,52$ & $3 \%$ & $\mathbf{R S S}$ & - & $0 \%$ & RS & $14.817 .623,41$ \\
\hline jul/1s & R\$ $14.208 .095,66$ & $97 \%$ & RS & $440.554,62$ & $3 \%$ & RS & - & $0 \%$ & RS & $14.648 .650,28$ \\
\hline ago/15 & $\mathrm{R} \$ \mathbf{1 3 . 4 9 4 . 3 8 5 , 8 4}$ & $94 \%$ & RS & $807.601,35$ & $6 \%$ & RSS & - & $0 \%$ & RS & 14.301.987,19 \\
\hline set/15 & RS $14.952 .093,48$ & $81 \%$ & RS & $3.064 .103,93$ & $17 \%$ & RS & $539.517,47$ & $3 \%$ & RS & $18.555 .714,88$ \\
\hline out/15 & R\$ $16.016 .583,35$ & $73 \%$ & RS & $5.484 .853,22$ & $25 \%$ & RS & $314.142,76$ & $1 \%$ & RS & $21.815 .579,33$ \\
\hline nov/15 & RS $14.810 .162,43$ & $70 \%$ & RS & $5.779 .869,28$ & $27 \%$ & RS & $635.359,08$ & $3 \%$ & RS & $21.225 .390,79$ \\
\hline $\mathrm{dez} / 15$ & RS $20.560 .101,07$ & $83 \%$ & RS & $3.100 .387,43$ & $13 \%$ & RS & $974.080,83$ & $4 \%$ & RS & $24.634 .569,33$ \\
\hline $\mathrm{jan} / 16$ & RS $15.411 .707,06$ & $87 \%$ & RS & $1.973 .574,55$ & $11 \%$ & RS & $332.344,15$ & $2 \%$ & RS & $17.717 .625,76$ \\
\hline $\mathrm{fev} / 16$ & $\mathrm{R} \$ \mathbf{1 6 . 1 9 0 . 1 1 2 , 9 7}$ & $87 \%$ & $\mathrm{RSS}$ & $1.565 .697,78$ & $8 \%$ & RSS & $766.366,83$ & $4 \%$ & $\mathrm{RS}$ & $18.522 .177,58$ \\
\hline $\mathrm{mar} / 16$ & RS $17.103 .965,35$ & $94 \%$ & RS & $556.571,62$ & $3 \%$ & RS & $584.457,48$ & $3 \%$ & RS & $18.244 .994,45$ \\
\hline$a b r / 16$ & RS $15.844 .875,86$ & $92 \%$ & RS & $866.959,75$ & $5 \%$ & RS & $557.475,89$ & $3 \%$ & RS & $17.269 .311,50$ \\
\hline $\mathrm{mai} / 16$ & RS $15.562 .119,97$ & $97 \%$ & $\mathrm{RS}$ & $538.466,90$ & $3 \%$ & RSS & - & $0 \%$ & RS & $16.100 .586,87$ \\
\hline jun/16 & RS $15.177 .723,01$ & $94 \%$ & RS & $328.162,20$ & $2 \%$ & RS & $563.415,72$ & $4 \%$ & RS & $16.069 .300,93$ \\
\hline \multirow[t]{2}{*}{ jul/16 } & RS $13.861 .948,91$ & $97 \%$ & $\mathrm{RS}$ & $380.749,28$ & $3 \%$ & RSS & - & $0 \%$ & RS & $14.242 .698,19$ \\
\hline & R\$ $289.642 .367,47$ & $91 \%$ & RS & $28.169 .080,08$ & $8 \%$ & $R S$ & $.267 .160,21$ & $1 \%$ & $\mathrm{RS}$ & $323.078 .607,76$ \\
\hline
\end{tabular}

FIGURA 4 - Faturamento 2015 e 2016 até julho

Fonte: Elaborado pelos autores

Organizações Rurais \& Agroindustriais, Lavras, v. 21, n. 1-3, p. 52-64, 2019 
Segundo resultados da Associação Brasileira das Indústrias Exportadoras de Carne (ABIEC) do ano de 2015, a produção de carne brasileira atingiu 9,56 milhões de toneladas equivalentes a carcaça (TEC). Destas, $80,37 \%$ se destinaram ao mercado interno e $19,63 \%$ ou 1,88 milhões TEC foram para exportações, onde $74,47 \%$ representaram a carne in natura, $11,44 \%$ carne industrializada e 11,40\%, miúdos e outros (ABIEC, 2016a).

Os $11,40 \%$ de exportações de miudezas são comercializados em 69 países, sendo o maior comprador Hong Kong, com 55\%, seguido pelo Egito, com $8 \%$ e demais países não citados nos resultados $37 \%$. A empresa destina suas exportações de miúdos para empresas estabelecidas em Hong Kong.

Segundo publicações da ABIEC, dados de 2015 e 2016 até julho e segundo as informações do SIGSIF, o Rio Grande do Sul é o $10^{\circ}$ colocado dentre os 22 Estados onde já se usa o SIGSIF, e $1^{\circ}$ colocado no abate de bufalinos

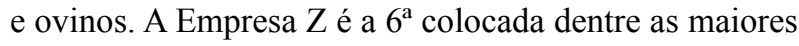
empresas abatedoras do estado Rio Grande do Sul, segundo dados obtidos através de entrevista informal com o Diretor do Sindicato da Indústria de Carnes e Derivados no Estado do Rio Grande do Sul (SICADERGS) (ABIEC, 2016b).

\subsection{Análise dos Dados}

Para a realização deste estudo foram analisados os meses de janeiro de 2015 a julho de 2016. Para a referida análise, realizou-se levantamento de informações de todas as compras de bovinos e bufalinos que a Empresa $\mathrm{Z}$ obteve neste período e, ainda se verificou-se se os créditos relacionados às compras estão de acordo com o percentual previsto no Decreto $\mathrm{n}^{\mathrm{O}}$ 41.620/02 (RIO GRANDE DO SUL, 2002).

Em relação ao Agregar Saídas, foi verificado no sistema de gestão da empresa se todos os produtos estavam com os seus percentuais cadastrados e de acordo com a legislação vigente. Após todas as verificações e análises nos relatórios contábeis e extra contábeis, foram identificadas divergências em diversos meses, o que gerou um retrabalho para a empresa em ajustar as informações que não estavam de acordo.

Como o sistema de gestão da empresa não estava totalmente adequado, optou-se em criar planilhas eletrônicas para assim, se ter um controle melhor, relacionando as compras dos animais, bem como, os abates diários. As planilhas eletrônicas ficaram a cargo do responsável pela parte fiscal da empresa, para viabilizar consultas e possíveis correções de informações de acordo com a legislação.

A Figura 5 apresenta a planilha de controle de entrada dos animais na empresa. Onde são lançadas as quantidades de cabeças de bovinos ou bufalinos, de acordo com a nota fiscal de entrada do produtor rural, bem como o valor de aquisição dos animais. A planilha serve também para o cálculo do estoque de animais vivos que ficaram no período. $\mathrm{O}$ valor do estoque é feito pelo preço médio das aquisições, multiplicado pela quantidade de cabeças que ficaram nos currais de espera para o abate.

\begin{tabular}{|c|c|c|c|c|c|c|c|c|c|c|c|c|}
\hline \multicolumn{2}{|c|}{ Dados Nota Fiscal } & \multicolumn{8}{|c|}{ Quantidade de Aninais por Nota Fiscal } & \multicolumn{3}{|c|}{ Valor da Nota Fiscal } \\
\hline Data da Nota & № Nota Fiscal & BOIS & NOVILHO & TOURO & VACA & NOVILHA & BUFAUNO & BUFAUINA & Total de Animais & & Nota Fiscal & Preço Médio \\
\hline \multirow[t]{3}{*}{$02 / 08 / 2016$} & 458253 & & 12 & & & & & & 12 & RS & $33.350,00$ & RS $2.779,17$ \\
\hline & 458253 & & & & 6 & & & & 6 & RS & $14.389,50$ & RS $2.398,25$ \\
\hline & 458253 & & & 1 & & & & & 1 & RS & $4.200,00$ & RS $4.200,00$ \\
\hline $04 / 08 / 2016$ & 458817 & & & & & 50 & & & 50 & RS & $108.067,00$ & RS $2.161,34$ \\
\hline \multirow[t]{2}{*}{$09 / 08 / 2016$} & 460040 & & & & 102 & & & & 102 & $\mathrm{RS}$ & $195.159,16$ & RS $1.913,33$ \\
\hline & 460040 & 132 & & & & & & & 132 & RS & $282,492,63$ & RS $2.140,10$ \\
\hline \multirow[t]{5}{*}{$16 / 08 / 2016$} & 461935 & & 50 & & & & & & 50 & RS & $138.294,00$ & RS $2.765,88$ \\
\hline & & & & & & & & & 0 & & & $\# 0 I V / 0$ ! \\
\hline & & & & & & & & & 5091 & RS & $2.378 .786,85$ & RS $2.431,50$ \\
\hline & & & & & & & & & Desconto senar & RS & $24.512,03$ & \\
\hline & & & & & & & & & Total: & & $12.354 .274,82$ & \\
\hline
\end{tabular}

FIGURA 5 - Controle de entrada de bovinos, ovinos e bufalinos Fonte: Elaborado pelos autores 
Como se pode analisar na Figura 5, a empresa adquiriu 5.091 cabeças e abateu 5.075 neste período, conforme a Figura 6. Por determinação dos órgãos responsáveis, após a chegada na empresa, os animais devem ficar 24 horas em descanso, somente recebendo água potável para a diminuição do calor corporal e o estresse da viagem, conforme determina o SIF e o Programa de bem-estar do animal.

A Figura 6 exemplifica o controle de abate. Onde são lançados todos os abates diários feitos na empresa, sendo que o total de abate no mês deve fechar com a mesma informação que é informada para o SIGSIF, conforme pode-se observar na Figura 3. Se as informações estiverem irregulares, solicitam-se os relatórios de notas emitidas, pois alguma nota fiscal ocasionou algum erro interno no sistema de gestão da empresa. Outro problema que foi encontrado refere-se ao procedimento de geração e importação de arquivos no programa SIGSIF. Foi evidenciado que ocorreu algumas notas não estavam sendo exportadas para o SIGSIF, o que acabou gerando um crédito menor no AGREGAR-RS CARNES sobre a entrada dos bovinos e bufalinos.

No Agregar Saídas também foram constatadas divergências nos percentuais de ICMS que a empresa poderia se apropriar. Como a Empresa $Z$ tem dois percentuais sobre as saídas de carnes havia alguns produtos que deveria estar gerando o crédito a $4 \%$ porém estavam cadastrados a $3 \%$. A Figura 7 apresenta a planilha de comparação do escritório contábil com as informações que a empresa declarou no agregar, conforme a Figura 3 do resumo do agregar. Como pode ser observado, o resumo apresentado pela empresa só traz as informações de compra e venda, não apresentando as informações das exportações.

Outro problema, encontrado na Figura 8, quando comparada com a Figura 3, são as devoluções de venda que se tinha no período de apuração do AGREGAR-RS CARNES saídas. O valor sobre elas não estava sendo descontado, do agregar saídas, pois como na venda se gerou o crédito do AGREGAR-RS CARNES saídas, na devolução da venda deverá se estornar a mesma proporção creditada.

As informações das planilhas contábeis, conforme Figura 7 e 8, são as informações que a empresa utilizará para a emissão das notas fiscais de crédito do Agregar Entradas e do Agregar Saídas. Destaca-se que o relatório do agregar da empresa é somente usado para fins de comparação para fechamento contábil.

Conforme ressalta Marion (1998), a contabilidade é o instrumento fundamental para o fornecimento de informações de uma empresa. O motivo da não utilização dos relatórios da Empresa Z, é pelo fato de não estarem de acordo com a legislação vigente, conforme o art. 32 do RICMS/RS e do Decreto ${ }^{\circ} 41.620 / 02$ (RIO GRANDE DO SUL, 2002), por não atenderem a legislação e pelo fato do relatório conforme Figura 3 não há como desconsiderar os valores das exportações de nem das devoluções de venda que se tem no período.

\begin{tabular}{|r|r|r|r|r|r|}
\hline \multirow{2}{*}{ Data da Matança } & \multicolumn{4}{|c|}{ Animal abatido no Dia } & \multirow{2}{*}{ Total } \\
\hline & \multicolumn{1}{|c|}{ BOI } & VACA & BUFALO & BUFALA & \\
\hline $01 / 08 / 2016$ & 93 & 125 & & & 218 \\
\hline $04 / 08 / 2016$ & 172 & 84 & & & 256 \\
\hline $05 / 08 / 2016$ & 184 & 92 & & & 276 \\
\hline $08 / 08 / 2016$ & 95 & 33 & & & 128 \\
\hline $10 / 08 / 2016$ & 82 & 81 & & & 163 \\
\hline $11 / 08 / 2016$ & 150 & 172 & & & 322 \\
\hline $12 / 08 / 2016$ & 223 & 33 & & & 256 \\
\hline $15 / 08 / 2016$ & 64 & 167 & & & 231 \\
\hline $17 / 08 / 2016$ & 104 & 102 & & & 206 \\
\hline $19 / 08 / 2016$ & 154 & 48 & & & 202 \\
\hline $23 / 08 / 2016$ & 150 & 81 & & & 231 \\
\hline $24 / 08 / 2016$ & 108 & 54 & & & 162 \\
\hline $29 / 08 / 2016$ & 15 & 202 & & & 217 \\
\hline $30 / 08 / 2016$ & 99 & 241 & & & 340 \\
\hline $31 / 08 / 2016$ & 92 & 94 & & & 186 \\
\hline
\end{tabular}

\begin{tabular}{l|l} 
Total abatidos no Mês & 5075 \\
\hline
\end{tabular}

FIGURA 6 - Resumo das matanças do mês

Fonte: Elaborado pelos autores

Organizações Rurais \& Agroindustriais, Lavras, v. 21, n. 1-3, p. 52-64, 2019 


\begin{tabular}{|c|c|c|c|c|c|c|}
\hline \multicolumn{2}{|c|}{ ENTRADAS DE BOVINO, OVINOS E BUFAUINOS } & \multicolumn{2}{|l|}{$08 / 2016^{\prime}$} & \multirow[b]{2}{*}{ VALORICMS } & \multirow[b]{2}{*}{ ISENTAS/NT } & \multirow[b]{2}{*}{ OUTROS } \\
\hline & & $\begin{array}{c}\text { VALOR } \\
\text { CONIABIL }\end{array}$ & BCICMS & & & \\
\hline 1101 & COMPRA GADO VIVO PAODUTOR RURAL - PF & $12.231 .493,62$ & - & . & . & $12.231 .493,62$ \\
\hline 1101.5 & COMPRA GADO VIVO PRODUTOR RURAL - PJ & $122.781,20$ & - & . & - & $122.781,20$ \\
\hline Export & $\begin{array}{l}\text { Desconto Senar } \\
\text { tarẵo no Mếs }\end{array}$ & $\begin{array}{r}12.354 .274,82 \\
24.512,03\end{array}$ & & & & \\
\hline 7101 & VENDA DE PROOUCAO DO ESTABELECIMENTO & $483.982,26$ & . & . & . & $\cdot$ \\
\hline & & Valor Base & $\begin{array}{l}\text { Valor Crédito } \\
\text { Agregar }\end{array}$ & Aliquota & $\begin{array}{c}\text { Dif. entre Lf } \\
\text { entrada } x \text { Rel. } \\
\text { Agregar }\end{array}$ & \\
\hline & Valor Informado Agrezar & $12.378 .786,85$ & $445.636,33$ & $3,60 \%$ & 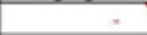 & \\
\hline & (-) Exportaça & $\begin{array}{rr} & 483.982 .26 \\
\end{array}$ & $17.423,36$ & $3,60 \%$ & & \\
\hline & Saldo a creditar & $11.894 .804,59$ & $428.212,97$ & $3,60 \%$ & & \\
\hline
\end{tabular}

FIGURA 7 - Cálculo do AGREGAR-RS CARNES: entradas

Fonte: Elaborado pelos autores

\begin{tabular}{|c|c|c|c|c|c|c|}
\hline SAIOAA & SDE CARNE & $08 / 2016$ & & & & \\
\hline \multicolumn{2}{|l|}{ Saidas } & VALOR CONTABIL & BCICMS & \multirow{2}{*}{ VALORICMS } & \multirow{2}{*}{ ISENTAS/NT } & \multirow{2}{*}{ OUtros } \\
\hline 5101 & VENDA DE PRODUCAO DO ESTABELECIMENTO & - & & & & \\
\hline 5401 & $\begin{array}{l}\text { VENDA PRODUCAO ESTABELECIMENTO OPERACE } \\
\text { (-)ST }\end{array}$ & $\begin{array}{r}14.259 .213,82 \\
293.283,98\end{array}$ & $8.146 .748,04$ & $977.607,52$ & $5.819 .181,80$ & . \\
\hline 6101 & VENDA DE PRODUCAO DO ESTABELECIMENTO & $1.367 .856,03$ & 797.911 .50 & $95.749,40$ & $569.944,53$ & . \\
\hline \multirow[t]{7}{*}{ TOTAL } & & 15.333.785,87 & $8.944 .659,54$ & 1.073.356,92 & $6.389 .126,33$ & - \\
\hline & & Valor Base & $\begin{array}{l}\text { Valor Crédito } \\
\text { Agregar }\end{array}$ & Aliquota & \begin{tabular}{|c|} 
Diferença \\
entre LF SAIDA \\
xAgregar \\
\end{tabular} & \\
\hline & Valor Informado Agrezar - Saidas Internas & $13.965 .930,71$ & $449.200,28$ & $3.22 \%$ & $\quad 0,87$ & \\
\hline & (-) Devolução de Vendas internas & - $18,092,64$ & 581,93 & & & \\
\hline & Valor Informado Agrezar - Saidas Interestaduais & $1.367 .856,03$ & $43.289,13$ & $3.16 \%$ & 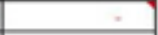 & \\
\hline & (-) Devolução de Vendas Interestaduais & - $\quad 3.592,31$ & 113,69 & & & \\
\hline & Saldo a creditar & $15.315 .694,10$ & $491.793,79$ & $3 \%$ & & \\
\hline
\end{tabular}

FIGURA 8 - Cálculo do AGREGAR-RS CARNES: saídas Fonte: Elaborado pelos autores

Todos os erros verificados foram ajustados em todos os relatórios, a fim de se chegar ao novo valor, tanto para o Agregar Carnes entradas como para o Agregar Carnes saídas. Diante de todos os problemas apontados, chegou-se no valor final que a empresa deixou de se creditar nos períodos analisados (Tabela 6). No Agregar Entradas, a diferença de crédito, a menor, alcançou o valor de R\$163.924,44. Porém, ao mesmo tempo, deveria fazer um estorno sobre as exportações, o qual não foi feito, no período de fevereiro de 2016, resultando, portanto, em diferença, a menor de R\$55.178,42.

No agregar saídas, a empresa deixou de se creditar de R\$ 319.304,50 e ainda precisou realizar um estorno de crédito apropriado a maior no mês de agosto de 2015 no valor de R \$11.735,97. Desta forma, o valor correspondente aos créditos não apropriados pela empresa no período de 01/01/2015 a 30/06/2016 chegou a $\mathrm{R} \$ 416.314,55$, conforme demonstrado na Tabela 6. 


\begin{tabular}{|c|c|c|c|c|}
\hline \multicolumn{5}{|c|}{ Diferenças encontradas } \\
\hline Mês & \multicolumn{2}{|c|}{ Agregar Entradas } & \multicolumn{2}{|c|}{ Agregar Saidas } \\
\hline jan/15 & RS & 176,40 & RS & - \\
\hline fev/15 & RS & $1.626,19$ & RS & - \\
\hline $\mathrm{mar} / 15$ & RS & - & RS & - \\
\hline $\mathrm{abr} / 15$ & $\mathrm{R} \$$ & - & $\mathrm{R} \$$ & - \\
\hline $\mathrm{mai} / 15$ & RS & - & RS & - \\
\hline jun $/ 15$ & $\mathrm{RS}$ & - & $\mathrm{RS}$ & $140.368,76$ \\
\hline jul/15 & RS & - & RS & $36.372,87$ \\
\hline ago/15 & $\mathrm{RS}$ & $39.138,69$ & $-\mathrm{RS}$ & $11.735,97$ \\
\hline set $/ 15$ & RS & 151,20 & RS & - \\
\hline out/15 & $\mathrm{RS}$ & $11.547,77$ & $\mathrm{R} S$ & - \\
\hline nov/15 & RS & $60.861,67$ & RS & $5.542,35$ \\
\hline dez/15 & $\mathrm{R} \$$ & $9.902,70$ & $\mathrm{R} \$$ & $99.315,90$ \\
\hline jan/16 & $\mathrm{RS}$ & $22.732,17$ & RS & 699,27 \\
\hline fev/16 & -RS & $55.178,42$ & RS & $12.416,20$ \\
\hline $\mathrm{mar} / 16$ & $\mathrm{R} \$$ & $4.538,24$ & $\mathrm{R} \$$ & $8.745,07$ \\
\hline \multirow[t]{2}{*}{$a b r / 16$} & $\mathrm{RS}$ & $13.249,41$ & RS & $15.844,08$ \\
\hline & Tota & ar Entradas & Tota & regar Saídas \\
\hline Crédito & RS & $163.924,44$ & $\mathrm{R} \$$ & $319.304,50$ \\
\hline Estorno & $-R S$ & $55.178,42$ & $-R S$ & $11.735,97$ \\
\hline
\end{tabular}

TABELA 6 - Diferenças encontradas Fonte: Elaboredo pelos autores

Para que os erros cometidos pela empresa decorrente da falta de estorno dos valores e pelos créditos a maior nos períodos, e que isso não seja considerado um ato ilícito (sonegação fiscal), como citado por Fabretti (2009) e Cassone (2000). Conforme demonstrado na Tabela 6, os valores creditados $(\mathrm{R} \$ 163.924,44+\mathrm{R} \$ 319.304,50=$ $\mathrm{R} \$ 483.228,94)$; foram revertidos através do debito ( $\mathrm{R} \$$ $55.178,42$ + R\$ 11.735,97), na apuração do ICMS da empresa nos meses em que foi verificadas as divergências, totalizando um crédito a ser utilizado no valor de $\mathrm{R} \$$ $416.314,55$. Como a empresa possui o benéficio do crédito presumido de ICMS, não poderá se recuperar deste ICMS apurado de uma única vez, pois por determinação do art. 32 do RICMS/RS, o saldo credor do mês não poderá ser apropriado no mês subsequente à apuração em que se tenha ficado com saldo credor de ICMS.

A Empresa $Z$ entrou com um processo administrativo junto à Secretaria da Fazenda do Estado do Rio Grande do Sul, para que possa se apropriar deste valor de ICMS não utilizado, ou seja, R $\$ 416.314,55$, no seu devido período, mas que é de direito, poder se creditar. Até a conclusão deste trabalho, não houve retorno da Secretaria da Fazenda quanto à solução do processo administrativo em tramitação.

\section{CONSIDERAÇÕES FINAIS}

Diante da alta carga tributária brasileira e da alta complexidade de seu Sistema Tributário, se faz necessário que as empresas tenham um bom planejamento tributário, pois o uso desta ferramenta de gestão possibilita a redução da arrecadação de tributos através de atos considerados lícitos.

Neste contexto, esta pesquisa buscou se aprofundar no art. 32 do RICMS/RS, que trata dos créditos presumidos de ICMS, concedidos às empresas estabelecidas no Estado do Rio Grande do Sul, bem como a importância de se manter os controles de acordo com a legislação, para a diminuição do ICMS devido. Buscou também um aprofundamento no Decreto $\mathrm{n}^{\circ} 41.620 / 02$, tema central da pesquisa, que trata dos créditos previstos para empresa do ramo de abate de bovino, ovinos e bufalinos. O Decreto ${ }^{\circ} 41.620 / 02$ (RIO GRANDE DO SUL, 2002) também trata sobre os procedimentos e normas que a empresa deve seguir quanto à aquisição de bovinos, ovinos e bufalinos e sobre as vendas de produtos comestíveis resultantes dos abates destes animais.

Realizou-se uma análise dos relatórios do AGREGARRS CARNES fornecidos pela Empresa Z, referente a janeiro de 2015 até julho de 2016. Diante de vários erros encontrados nas informações prestadas pela empresa, fez-se necessário

Organizações Rurais \& Agroindustriais, Lavras, v. 21, n. 1-3, p. 52-64, 2019 
elaborar uma planilha eletrônica para apurar os valores corretos do Agregar Carnes entradas e do Agregar Carnes saída de maneira correta e dentro da legislação vigente. A utilização da planilha ocorreu sob a forma de relatório padrão para as apurações dos valores de entrada de bovinos e bufalinos na empresa, bem como do abate dos mesmos e para os controles do AGREGAR-RS CARNES entradas e saídas. A pesquisa se mostrou muito importante para a empresa, pois diante dos valores apresentados, ela poderá ter uma redução no seu ICMS a pagar nos próximos meses, em decorrência do crédito de R\$ 416.314,55 não compensado em momento oportuno, em caso de decisão favorável da Sefaz/RS, o que pode proporcionar recursos a serem investidos em outras áreas da empresa, identificando desta forma o impacto tributário que representa uma análise detalhada sobre o crédito presumido de ICMS conforme determina o Decreto 41.620/02 .

Aos objetivos, pode-se afirmar que os mesmos foram atingidos, sendo que no primeiro deles buscava contextualizar o art. 32 do RICMS/RS, que trata sobre os créditos presumidos de ICMS, concedidos as empresas estabelecidas no Estado do Rio Grande do Sul, e também a contextualização do Decreto $n^{\circ}$ 41.620/02 (RIO GRANDE DO SUL, 2002), que foi o tema principal desta pesquisa que trata sobre os créditos do AGREGAR-RS CARNES, e das normas e legislações que as empresas abatedoras de bovinos, ovinos e bufalinos devem seguir para se ter o benefício do crédito presumido de ICMS e para se manterem no programa. Posteriormente, buscou-se analisar e comparar a legislação vigente do art. 32 do RICMS/RS e do Decreto $n^{\circ} 41.620 / 02$ se as informações prestadas pela empresa estavam de acordo com a legislação vigente. Por fim, visou-se identificar os erros que a empresa tinha no AGREGAR-RS CARNES. Diante dos resultados encontrados foram solicitadas as devidas correções dos erros identificados para que a empresa atendesse as normas e a legislação vigente sobre o art. 32 do RICMS/RS e ao Decreto n ${ }^{\circ}$ 41.620/02. Desta forma, considerando a pergunta de pesquisa, que é: "Qual é o impacto sobre a carga tributária decorrente da desatualização das informações junto ao controle do Programa Estadual de Desenvolvimento, Coordenação e Qualidade do Sistema Agroindustrial da Carne de Gado Vacum, Ovino e Bufalino (AGREGAR-RS CARNES)?”, é possível afirmar que sim, houve o impacto sobre a carga tributária, pois foi identificado o valor do crédito que a empresa deixou de se apropriar e precisou entrar com processo administrativo para utilizar a compensação.

Como limitação para a realização desta pesquisa, pode-se mencionar a literatura escassa sobre o assunto, pois sendo dois Decretos limitou-se ao uso da legislação, o que muitas vezes não deixou claro os assuntos. As diversas pesquisas e entrevistas feitas não proporcionavam respostas precisas, pois haviam divergências entre os entendimentos. Apesar de todas as limitações pode-se dizer que os objetivos desta pesquisa foram alcançados, o que permite que outras empresas do mesmo ramo da Empresa $Z$ e que estejam enquadradas no Programa AGREGAR-RS CARNES, possam utilizar esta pesquisa como fonte de informações.

A pesquisa aplicada visa contribuir tanto para o meio acadêmico como para a sociedade em geral, servindo de suporte para as organizações que vierem a apresentar as mesmas características da Empresa Z. Vale destacar que não foram localizados muitos trabalhos acadêmicos que tratem desse tema, nesse sentido a presente pesquisa propõe agregar informações e conhecimento para os usuários.

Assim, sugere-se para as próximas pesquisa, o estudo relacionado as compras de carne vindas de outros estados da Federação se baseando na Instrução Normativa DRP $n^{\circ}$ 045/98, que trata das Mercadorias oriundas de outras unidades da federação beneficiadas com incentivo ou favor fiscal ou financeiro-fiscal em desacordo com a Lei complementar $n^{\circ} 24 / 75$. Ou também tratar de como serão os créditos de ICMS nas importações de bovinos vivos vindo de outros países como o Uruguai para a produção de carne uruguaia.

\section{REFERÊNCIAS}

ASSOCIAÇÃO DAS INDÚSTRIAS BRASILEIRAS DE CARNES. Perfil da pecuária no Brasil: relatório anual 2016. 2016b. Disponível em: http://www.newsprime. com.br/img/upload2/2016_FolderPerfil_PT.pdf. Acesso em: 02 set. 2016.

ASSOCIAÇÃO DAS INDÚSTRIAS BRASILEIRAS DE CARNE. Estatísticas: abates. 2016a. Disponível em: http:// www.abiec.com.br/texto.asp? id=7. Acesso em: 02 set. 2016.

BARDIN, L. Análise de conteúdo. São Paulo: Edições 70, 2011.

BRASIL. Lei no $\mathbf{1}^{\mathbf{2} 283}$, de 18 de dezembro de 1950. Dispõe sobre a inspeção industrial e sanitária dos produtos de origem animal. Diário Oficial da União, Brasília, DF, 1950.

BRASIL. Decreto $\mathbf{n}^{\mathbf{0}}$ 30.691, de 20 de março de 1952 . Aprova o novo Regulamento da Inspeção Industrial e Sanitária de Produtos de Origem Animal. Diário Oficial da União, Brasília, DF, 1952. 
BRASIL. Lei no 10.833, de 29 de dezembro de 2003. Altera a Legislação Tributária Federal e dá outras providências. Diário Oficial da União, Brasília, DF, 30 dez. 2003.

BRASIL. Lei 1.283, de 18 de dezembro de 1950. Dispõe sobre a inspeção industrial e sanitária dos produtos de origem animal. Disponível em http://www.planalto.gov. br/ccivil_03/LEIS/L1283.htm. Acesso em 19 set. 2016

CASSONE, V.; CASSONE, M. E. T. Processo tributário: teoria e prática. 2 ed. São Paulo: Atlas, 2000.

FABRETTI, L. C. Direito tributário aplicado: impostos e contribuições das empresas. 2. ed. São Paulo: Atlas, 2009.

FARSUL. Relatório Econômico 2017 e Perspectivas 2018. 2017. Sistema Farsul. Disponível em: http://www. assessoriaagropecuaria.com.br/anexo/147. Acesso em 27 dez. 2017.

MARION, J. C. Contabilidade básica. 6. ed. São Paulo: Atlas, 1998.

MINistÉRIO DA AGRICUlturA. Comissão de Bem-estar animal. 2016 a. Disponível em: http://www. agricultura.gov.br/animal/bem-estar-animal. Acesso em: 19 set. 2016.

MINISTÉRIO DA AGRICUlTURA. Dipoa. 2016 b. Disponível em: http://www.agricultura.gov.br/animal/ dipoa. Acesso em: 01 set. 2016.

MINISTÉRIO DAAGRICULTURA. Exportação. 2016c. Disponível em: http://www.agricultura.gov.br/animal/ exportacao. Acesso em: 07 set. 2016.

MINistériO DA AGRICULTURA. Normas Técnicas de Instalações e equipamentos para MatadourosFrigoríficos de Bovinos e Bufalinos. 2016d. Disponível em: http://www2.agricultura.rs.gov.br/ uploads/12675551291178622989Matadouro_frigorifico_ de_Bovinos.pdf. Acesso em: 08 set. 2016.

MINISTÉRIO DAAGRICULTURA. Serviço de Inspeção Federal - SIF. 2016e. Disponível em: http://www. agricultura.gov.br/sif. Acesso em: 07 set. 2016.

MINISTÉRIO DA AGRICULTURA. Sisbov. $2016 \mathrm{f}$. Disponível em: http://www.agricultura .gov.br/animal/ rastreabilidade/sisbov. Acesso em: 19 set. 2016.
MINISTÉRIO DA AGRICULTURA. Rastreabilidade. 2016g. Disponível em: http://www.agricultura.gov.br/ animal/rastreabilidade. Acesso em: 07 set. 2016.

PRODANOV, C. C.; FREITAS, E. C. Metodologia do trabalho científico. Novo Hamburgo: Feevale, 2009.

PRODANOV, C. C.; FREITAS, E. C. Metodologia do trabalho científico: métodos e técnicas da pesquisa e do trabalho científico. 2. ed. Novo Hamburgo: Feevale, 2013.

RAUPP, F. M.; BEUREN, I. M. Metodologia da pesquisa aplicável às ciências sociais. In: BEUREN, I. M. (org.). Como elaborar trabalhos monográficos em contabilidade: teoria e prática. 3. ed. São Paulo: Atlas, 2006.

REZENDE, A. J.; PEREIRA, C. A.; ALENCAR, R. C. Contabilidade tributária: Entendendo a lógica dos tributos e seus reflexos sobre o resultado das empresas. São Paulo: Atlas, 2010.

RIO GRANDE DO SUL. Decreto n ${ }^{\circ} 37.699$, de 26 de agosto de 1997: Aprova o Regulamento do Imposto sobre Operações Relativas à Circulação de Mercadorias e sobre Prestações de Serviços de Transporte Interestadual e Intermunicipal e de Comunicação (RICMS). Diário Oficial do Estado, Porto Alegre, 26 ago. 1997.

RIO GRANDE DO SUL. Decreto n ${ }^{\circ} 41.620$, de 20 de maio de 2002. Institui o Programa Estadual de Desenvolvimento, Coordenação e Qualidade do Sistema Agroindustrial da Carne de Gado Vacum, Ovino e Bufalino - AGREGARRS CARNES. Diário Oficial do Estado, Porto Alegre, 21 mai. 2002.

ROCHA, C. B.; PARRÉ, J. L. Estudo da Distribuição Espacial do Setor Agropecuário do Rio Grande do Sul. Revista Análise Econômica, Porto Alegre/RS, v. 27, n. 52, 2009.

SECRETARIA DA AGRICULTURA, PECUÁRIA E IRRIGAÇÃO. Programa Agregar Carnes RS. 2016. Disponível em: http:/www.agricultura.rs.gov.br/ conteudo/824/?Programa_Agregar_Carnes_RS. Acesso em 29 ago. 2016.

YIN, R. K. Estudo de caso: planejamento e métodos. 4. ed. Porto Alegre: Bookman, 2010.

Organizações Rurais \& Agroindustriais, Lavras, v. 21, n. 1-3, p. 52-64, 2019 